\title{
Cenlestao
}

\section{Redes de Citação: estudo de rede de pesquisadores a partir da competência em informação}

\author{
Marcos Moraes \\ Mestre; Universidade Estadual de Londrina (UEL), Londrina, PR, Brasil; \\ marcomoraes@msn.com \\ Renata Lira Furtado \\ Doutoranda; Universidade Estadual de Londrina (UEL), Londrina, PR, Brasil; \\ re23br@gmail.com \\ Maria Inês Tomaél \\ Doutora; Universidade Estadual de Londrina (UEL), Londrina, PR, Brasil; \\ mitomael@gmail.com
}

\begin{abstract}
Resumo: No âmbito da comunicação científica, pesquisadores vêm utilizando a metodologia de Análise de Redes Sociais (ARS) a fim de investigar como ocorre o relacionamento entre pesquisadores/instituições de ensino e pesquisa, organizações e documentos. A pesquisa presente neste artigo se insere nesse contexto: o objetivo foi mapear uma rede de citação dos autores que publicaram trabalhos sobre Competência em Informação (CI) na base de dados Scopus no ano de 2012. Foi utilizada a ARS em conjunto com aspectos técnicos da Análise de Citação para atingir ao objetivo proposto. A rede analisada apresentou um grau de densidade muito baixo, ou seja, houve um baixo índice de citação entre os autores; diferentemente das autocitações, que foram observadas em um número bastante alto. Foi possível constatar que determinados autores exercem grande importância por serem bastante citados pelos colegas. No caso da rede em questão, Christine Bruce foi identificada como a mais citada pelos colegas. Novas pesquisas similares podem ser realizadas se analisados outros períodos e canais de comunicação a fim de estabelecer comparações para se adensar o conhecimento sobre o comportamento dos pesquisadores dessa área.
\end{abstract}

Palavras-chave: Análise de redes sociais. Redes de citação. Competência em Informação. Análise de citação.

\section{Introdução}

Num sentido bastante amplo, as redes sociais nos permitem compreender a sociedade como um conjunto de indivíduos (ou organizações, instituições, documentos, entre outros) que se relacionam permanentemente entre si, de modo que este relacionamento se caracteriza por vínculos dinâmicos que realizam diversas 
atividades, tais como troca de conhecimento, informação, sentimentos, produtos, entre outros. De maneira geral, tudo está conectado em redes, no qual cada uma delas se desenvolve de maneira bastante peculiar, levando em consideração as suas particularidades.

As pessoas estão inseridas na sociedade por meio das relações que desenvolvem durante toda sua vida, primeiro no âmbito familiar, em seguida na escola, na comunidade em que vivem e no trabalho; enfim, as relações que as pessoas desenvolvem e mantêm é que fortalecem a esfera social. A própria natureza humana nos liga a outras pessoas e estrutura a sociedade em rede. (TOMAÉL; ALCARÁ; DI CHIARA, 2005, p. 93).

As redes de conhecimento e informação vêm sendo alvo de vários estudos acadêmicos que buscam investigar o funcionamento das mesmas, levantando questões importantes para seu melhor desenvolvimento.

No âmbito da comunicação científica, trabalhos que têm como objetivo estudar as relações ocorridas nesse ambiente com a utilização da metodologia de ARS buscam investigar como ocorre o relacionamento entre pesquisadores/instituições de ensino e pesquisa, organizações e documentos. A pesquisa presente neste artigo se insere nesse contexto ao estudar uma rede de conhecimento científico por meio da análise de citação.

Para a comunicação científica, a citação aponta para uma relação com trabalhos já existentes, ou seja, quando um pesquisador utiliza um conhecimento e o menciona em seu texto, ele estabelece uma ligação com outro pesquisador. Desse modo, este trabalho objetiva, ao evidenciar essa relação por meio da citação, mapear uma rede de citação dos autores que publicaram trabalhos sobre CI publicados na base de dados Scopus no ano de 2012.

Foi utilizada a abordagem teórico-metodológica da ARS, que envolve o estudo das várias métricas utilizadas para investigar o funcionamento das redes. Para atingir o objetivo proposto, foram utilizados, em conjunto com a ARS, aspectos técnicos da análise de citação. A combinação da ARS com outras técnicas de pesquisa vem se mostrando bastante apropriada, na medida em que amplia as possibilidades de investigações relacionadas às redes sociais.

Para contextualizar a pesquisa, foi realizada uma revisão de literatura abrangendo sobretudo artigos científicos, com o intuito de identificar aspectos 
teóricos importantes da CI, da análise de citações, da comunicação científica e da ARS, temas centrais do presente estudo.

\section{Competência em Informação}

A expressão "Competência em Informação" é uma das traduções do termo Information Literacy, que surgiu na literatura em 1974, no relatório elaborado pelo bibliotecário americano Paul Zurkowski e intitulado The information service environment relationships and priorities. Esse documento descreve uma série de produtos e serviços de informação providos por instituições privadas e suas relações com as bibliotecas. Tal documento preconizava que as pessoas treinadas na aplicação de recursos informacionais são consideradas competentes, pois aprenderam técnicas e habilidades para a utilização de ferramentas informacionais e fontes primárias a fim de criar soluções para problemas (DUDZIAK, 2001).

Os primeiros estudos sobre Competência em Informação no Brasil estiveram associados à educação de usuários diante das possibilidades de desenvolver habilidades relacionadas à informação em bibliotecas. Esses estudos culminaram com o processo de valorização da informação como produto e nos avanços das Tecnologias de Informação e Comunicação (TIC), momento em que o desenvolvimento de habilidades que permitem o acesso físico e intelectual aos recursos informacionais tornou-se necessário.

O termo Information Literacy foi traduzido como Maîtrise de l'Information na França, Alfabetización Informacional (Alfin) na Espanha e Desarrollo de Habilidades Informativas - DHI, utilizada na maior parte pelo México. No Brasil, o termo Information Literacy recebeu várias traduções, sendo que as mais utilizadas são: Alfabetização Informacional, Letramento Informacional, Competência Informacional e Competência em Informação. Cada um apresenta seu próprio conteúdo semântico, além de diferenças caracterizadas pelo tipo de habilidades, o nível, as categorias de aprendizagem e os métodos pedagógicos (HORTON, 2008; LAU, 2007).

Gasque (2013) evidencia que os conceitos são diferentes, mas que estão inter-relacionados, e que, além disso, a adoção de um arcabouço conceitual 
relaciona-se às concepções, paradigmas e experiências do próprio pesquisador. A autora enfatiza os conceitos como um processo que ocorre de forma sistematizada, em que os aprendizes devem apreender os conteúdos relacionados aos padrões de letramento e também aplicá-los para resolver problemas. Tal processo tem início com a alfabetização informacional, por meio dos primeiros contatos com os conceitos informacionais e, em sequência, na consolidação e aplicação dos conhecimentos para a resolução de problemas e na tomada de decisões, caracterizando as competências que são adquiridas por intermédio do desenvolvimento de habilidades específicas.

Assim, fica evidente que não há um consenso terminológico e conceitual para as expressões em português. No XIII Seminário Nacional de Bibliotecas Universitárias (SNBU), realizado na cidade de Natal/RN em 2004, foi proposta a utilização do termo "Competência em Informação", que tem sido reconhecido e utilizado desde então por muitos pesquisadores da área (HATSCHBACH; OLINTO, 2008).

Para Horton Jr. (2008), o termo “Competência em Informação" está intimamente aliado ao "aprender a aprender" e ao pensamento crítico. Segundo o autor, é o conjunto de atitudes e conhecimentos necessários para saber quando a informação é necessária para ajudar a resolver um problema ou tomar uma decisão, bem como articular esta informação precisa em termos e linguagem pesquisáveis; em seguida, para que se possa procurar as informações de forma eficiente, além de recuperar, interpretar, entender, organizar e avaliar a sua credibilidade e autenticidade, avaliar a sua relevância e comunicá-la aos outros.

Para Lau (2007), uma pessoa competente em informação deve saber como se beneficiar do mundo de conhecimentos para incorporar a experiência de outros em seu próprio acervo de conhecimentos. Essa é uma definição próxima da proposta por Gasque (2013), que se refere à CI como a capacidade do aprendiz em mobilizar o próprio conhecimento que o ajuda na tomada de decisão em determinada situação.

A American Library Association (2000) conceitua a CI como um conjunto de habilidades indispensáveis ao indivíduo para reconhecer quando uma informação é necessária, além de ter habilidades para localizá-la, avaliá-la e usá-la eficazmente. Já 
Hatschbach (2002), corrobora com a definição da ALA e acrescenta que essa é uma área de estudos e de práticas que tratam das habilidades acerca do uso da informação em relação à sua busca, localização, avaliação e divulgação, integrando a utilização de novas tecnologias e a capacidade de resolução de problemas em informação.

Para Monereo e Badia (2012), o desenvolvimento da CI deveria contemplar três blocos de aprendizagem fundamentais: a interpretação adequada da demanda informacional e das condições de resolução de tarefas; a aquisição de conhecimentos de diferentes naturezas para a abordagem competente das tarefas em questão e o desenvolvimento de diferentes níveis de regulação do processo de resolução da tarefa informacional.

Dudziak (2001), ao abordar o desenvolvimento da CI, relaciona-o ao processo de aquisição de conhecimentos e habilidades em diferentes contextos ao longo da vida, representados por três concepções: a informação, com ênfase nas tecnologias, envolvendo as habilidades de operação e comunicação por meio de computadores, bem como a compreensão do funcionamento de equipamentos, programas e aplicações e, ainda, a produção, organização, disseminação e acesso de formas automatizadas com vistas a resolver problemas por meio do uso da tecnologia; o conhecimento, com ênfase nos processos cognitivos, no qual ocorre o processo de busca da informação para a construção do conhecimento; e a inteligência, com ênfase no aprendizado ao longo da vida, que engloba não só conhecimentos e habilidades, como também a noção de valores atrelada à dimensão social do indivíduo, incluindo valores como ética, autonomia, responsabilidade, criatividade, pensamento crítico e "aprender a aprender", com ênfase no cidadão enquanto ser social.

\section{Análise de Citação}

A Associação Brasileira de Normas Técnicas (2003, p. 2) define 'Citação' como a "menção de uma informação extraída de outra fonte". Assim, a partir da citação, um documento remete a outro, estabelecendo inter-relação entre eles. As citações em trabalhos acadêmicos são utilizadas para estabelecer ligações com outros trabalhos 
já produzidos (JAN, 2009).

A Análise de Citações baseia-se na premissa de que os pesquisadores concebem seus trabalhos a partir de obras anteriores e demonstram isso citando as obras precedentes em seus textos e em uma lista ordenada e padronizada de referências. O comportamento dos cientistas fica evidente a partir do estudo dessas citações (MOREL; MOREL, 1977).

Desse modo, e diante da importância que as referências bibliográficas representam num trabalho científico, a análise dessas referências, que são denominadas no campo da bibliometria como Análise de Citação, vem sendo empregada como um importante instrumento metodológico de mapeamento da produção intelectual de diversas áreas do conhecimento. O emprego da Análise de Citação serve para diversas finalidades como a indicação de tendências de temáticas de pesquisa, indicadores de citação e mapeamento de áreas do conhecimento mais citadas em determinada produção científica.

Nos estudos de citação, dois recursos científicos indissociáveis se destacam: a citação e a referência. A citação representa o registro de ideias apreendidas de textos em um texto, enquanto que a referência é o registro da fonte das ideias apreendidas pelo autor de determinado texto (SILVEIRA; BAZI, 2009).

A Análise de Citação mede o impacto e a visibilidade de autores dentro de uma comunidade científica, evidenciando as escolas do pensamento que vigoram dentro de determinados campos da ciência. A técnica tem um caráter evidentemente quantitativo, e tem sido utilizada por pesquisadores da CI para diversas finalidades, tais como: mensurar o impacto de revistas científicas; analisar quantitativamente a produção científica de periódicos, autores, grupos de pesquisa, áreas do conhecimento e instituições; mapear temas de maior publicação e interesse dentro de uma área ou canal de publicação, entre outros objetivos.

A técnica é utilizada, também, para a identificação de fontes de informação selecionadas por cientistas e pesquisadores para fundamentar seus estudos a partir do levantamento de variáveis quantitativas. Os documentos citados por um autor são valiosas fontes de dados que são utilizadas para a análise de uso e para mensurar as demandas de informação. Estudar as fontes de informação escolhidas por uma 
comunidade científica permite o mapeamento de características da dinâmica de seus processos de comunicação científica.

Na medida em que a ciência possui como um dos seus principais produtos os textos científicos publicados em revistas periódicas, as citações contidas nestes textos assumem uma importância essencial.

Cada citação, nesse contexto, representa uma ligação entre dois atores de uma rede científica. Esse elo pode representar algumas características importantes de determinados grupos de cientistas, visto que a citação, no âmbito acadêmico, apresenta dois principais aspectos: o cognitivo ou epistemológico, que indica os pressupostos teóricos utilizados pelo autor, e também o social, que por sua vez revela práticas pessoais ou de determinados grupos.

É esse aspecto que enseja possibilidades de uso das citações no estudo da ciência de maneira mais ampla, pois o nível micro (a citação) conecta-se com o macro (o sistema de comunicação científica da qual a citação faz parte) (ROMANCINI, 2010, p. 20).

Griffith (1989) aponta que a comunicação científica compreende atividades associadas à produção, disseminação e uso da informação científica a partir do momento em que o cientista concebe uma ideia para pesquisar, assim que isso é feito, os resultados provenientes da pesquisa podem ser aceitos pela comunidade científica, ou não, como parte constituinte do estoque universal de conhecimentos.

A comunicação científica proporciona a disseminação do conhecimento científico entre os cientistas, otimizando o acesso e apropriação dessas informações para o desenvolvimento de outras pesquisas, para assim, corroborar ou refutar os resultados de pesquisas anteriores, ou ainda, fomentar novas perspectivas em um determinado campo científico. Também, possibilita o estabelecimento de outras disciplinas e áreas de estudo e contribui, assim, para o conhecimento humano de um modo geral. Em síntese, esse é o modus operandi que vigora na comunicação científica, entretanto, é a comunidade científica, formada em sua maioria por pesquisadores, que conduz os processos que culminam na publicação de pesquisas científicas.

A comunidade científica é uma associação de pessoas que não estão vinculadas entre si por leis nem por cadeias de comando, mas pela comunicação de informações - através de revistas especializadas, 
conferências, discussões informais e outros canais. A comunicação é coordenada por instituições tais como as sociedades de especialistas e colégios invisíveis. Por meio dessas instituições e canais, e do mecanismo de recompensa que opera através deles, a comunidade científica procura atingir certos objetivos que contribuem para o propósito geral de ampliar o conhecimento da natureza. Esses objetivos consistem em manter padrões de pesquisa, harmonizar os interesses do cientista individual e da empresa científica, promover a competição e a cooperação, e estimular a inovação. (KNELLER, 1980, p. 182).

Ainda que a comunidade científica se configure em uma associação de pessoas (cientistas) que não estão vinculadas entre si por leis, nem por cadeias de comando, existem normas e padrões amplamente aceitos e utilizados pela comunidade a fim de estabelecer formas adequadas e seguras para disseminar o conhecimento científico, além de garantir reconhecimento e mérito pela pesquisa, conferindo impacto e visibilidade aos pesquisadores e suas pesquisas, o que muitas vezes garante a contiguidade de seus trabalhos.

As citações, dentro de uma Comunicação Científica, é um dos mecanismos utilizados para aferir o reconhecimento de pesquisas já publicadas, uma vez que permitem identificar a própria pesquisa, os autores, periódicos, instituições e outros dados que serviram de respaldo em dado momento. Dessa forma, a análise dessas citações surge como uma técnica apropriada para estudos diversos no campo da comunicação científica.

\section{Análise de Redes Sociais}

Uma rede social pode ser definida como uma estrutura que identifica os caminhos pelos quais os elementos estão ligados a outros. Ela representa um conjunto de participantes autônomos, unindo ideias e recursos em torno de valores e interesses compartilhados, no qual há a valorização dos elos informais e das relações em detrimento das estruturas hierárquicas (MARTELETO, 2001).

As redes sociais estão por toda parte. Aliás, tudo está ligado por redes: pessoas, organizações, instituições, grupos, documentos, e assim por diante. A atual dinâmica social, no qual a internet e a globalização já estão imbricadas no dia a dia das pessoas, há uma maior evidência das redes sociais se comparada às épocas anteriores. Desse modo, o fenômeno das redes sociais ganhou importância, e estudos 
que buscam investigar seu funcionamento começaram a surgir e aumentaram gradativamente nas últimas décadas.

A ARS é uma metodologia oriunda da Antropologia Cultural e da Sociologia, mas com aplicações em diversas disciplinas, cujo foco analítico recai sobre as relações e interações entre os indivíduos, como maneira de entender a estrutura relacional da sociedade (MARTELETO; TOMAÉL, 2005).

Para Sousa (2007), a ARS é uma abordagem desenvolvida por Moreno em meados da década de 1930, para a demonstração do comportamento social e psicológico, em que as relações interpessoais eram representadas graficamente de acordo com um sociograma, matriz que demonstra as relações entre as pessoas.

A ARS estuda padrões de relacionamentos entre pessoas, grupos, organizações, países, acontecimentos, etc. que representam "nós" na rede que são denominados de "atores", podendo representar uma unidade de análise relevante. Esses padrões de relacionamento dentro de uma rede são analisados pela ARS por meio de algumas métricas que revelam diversas características das relações. Neste trabalho, apresentamos as métricas de densidade, cliques e centralidades.

A densidade é uma das medidas mais importantes da ARS, é considerada como uma das medidas mais amplas da estrutura de rede social, porque explicita o número de ligações existentes no momento em que a rede é mapeada (MARTELETO; TOMAÉL, 2005). É definida como o número de ligações diretas e reais dividido pelo número de possíveis ligações diretas em uma rede (KADUSHIN, 2012). Sabe-se que a densidade das relações entre os atores da rede depende fortemente do tamanho de um grafo, ou seja, do número de atores que compreende: quanto mais elevado for esse número, menor será a densidade (LEMIEUX; OUIMET, 2008).

O clique é considerado como um subgrupo de uma rede, pois os atores mantêm relações mais fortalecidas e estão mais densamente conectados em relação aos demais membros da mesma rede. Assim, para que se possa caracterizar a existência de um clique, deve-se existir, no mínimo, três atores que se conectem intensamente. (MARTELETO; TOMAÉL, 2005).

A centralidade é uma métrica que evidencia a posição dos participantes de 
uma rede, apontando aqueles que possuem posição mais privilegiada em diversos aspectos, tais como proximidade e intermediação. Os atores centrais de uma rede ocupam uma posição-chave ou privilegiada, visto que podem absorver melhor a informação contida nos canais comunicacionais (HANNEMAN, 2001).

\begin{abstract}
A centralidade é, então, a posição de um indivíduo em relação aos outros, considerando-se como medida a quantidade de elos que se colocam entre eles. $\mathrm{O}$ fato de os indivíduos com mais contatos diretos em uma rede não serem exatamente aqueles que ocupam as posições mais centrais pode ser explicado através do conceito de abertura estrutural. Um indivíduo com poucas relações diretas pode estar muito bem posicionado em uma rede por meio da utilização estratégica de suas aberturas estruturais. (MARTELETO, 2001, p. 76).
\end{abstract}

A centralidade de grau é uma medida que reflete a atividade relacional direta de um ator ao medir o número de ligações diretas de cada um deles num grafo (LEMIEUX; OUIMET, 2008). Hanneman (2001) aponta que quando um ator dispõe de muitas ligações, ele é considerado bem posicionado na rede, já que possui relações diversas com outros membros da mesma, favorecendo futuras interações.

A centralidade de proximidade é uma medida que se assenta na distância geodésica, ou seja, no comprimento do caminho mais curto que liga dois atores. (LEMIEUX; OUIMET, 2008). Marteleto (2001) esclarece que a centralidade de proximidade de um ator mostra a sua independência em relação aos outros, pois será visto como central por poder evitar o controle dos canais de comunicação da rede e, assim sendo, os atores não centrais deverão transmitir suas informações por intermédio de outros.

Os atores mais centrais em proximidade são considerados independentes, pois quando necessitam de uma intermediação com outro membro da rede, percorrem um caminho mais curto para alcançar os outros pontos da rede, não dependendo, assim, de intermediários.

A centralidade de intermediação é definida como o potencial daqueles atores que servem como intermediários, ou seja, mede o quanto um ator atua como ponte, facilitando as ligações entre os diversos atores da rede (KADUSHIN, 2012).

\title{
5 Metodologia
}


A base de dados Scopus foi escolhida para a busca e coleta dos artigos publicados por todas as revistas indexadas pela base ao longo do ano de 2012 que tratem da temática da Competência em Informação.

A pesquisa foi realizada na interface de busca da Scopus, utilizando o termo em inglês "Information literacy", com o intuito de localizar os artigos publicados em 2012 que continham o termo no título do trabalho. Foram recuperados 114 artigos com as características desejadas.

Foi utilizado o programa End Note para recuperar os dados bibliográficos dos 114 artigos bem como a lista completa de referências de todos os trabalhos. Os dados foram sistematizados utilizando a planilha do UCINET e o Office Word da Microsoft. Foram organizados na planilha os nomes de todos os autores dos trabalhos encontrados, totalizando em 214 autores. No Office Word foram sistematizadas as referências dos artigos, a autoria e a lista de referências (citações) de cada artigo.

Com os dados sistematizados, procedeu-se assim o preenchimento da planilha no UCINET, verificando se cada um dos 214 autores havia sido citado pelos outros autores nos 114 trabalhos recuperados, excluindo os casos de autocitação. Na sequência, foram geradas as métricas e os gráficos no NetDraw.

O Ucinet é um software que possibilita a identificação de medidas das redes. Foi desenvolvido por Borgatti, Everett e Freemann (2002), com o propósito de auxiliar a análise das redes sociais. O software caracteriza as ligações entre atores por meio de gráficos provenientes de uma matriz e, pela aplicação de algoritmos específicos, que possibilitam o cálculo de medidas e a configuração das redes. Integrado ao Ucinet está o Netdraw, programa para representação de diagramas, que possibilita a visualização de dados de redes sociais. Também foi desenvolvido por Borgatti e permite visualizar relações múltiplas, distinguir atributos para atores da rede, salvar os diagramas da rede como imagem, além de outros recursos (MARTELETO; TOMAÉL, 2005, p. 97).

O software examina automaticamente, por meio das ligações entre os autores, várias categorias de análise possíveis a fim de investigar relações entre os participantes da rede. As categorias analisadas pelo UCINET para esta pesquisa e que foram arroladas nos resultados são as seguintes: diagrama da rede, densidade, cliques, centralidade de grau, grau de proximidade e grau de intermediação. 


\section{Resultados}

É importante esclarecer que as autocitações não foram incluídas na planilha do UCINET uma vez que a existência de sinais que indicam ligações entre os mesmos atores da rede podem causar problemas ao gerar algumas métricas. A autocitação caracteriza-se pelo ato de mencionar trabalhos anteriores do próprio autor no trabalho que o mesmo está produzindo. Foi identificado um número bastante elevado de autocitação. No quadro a seguir são listados todos os autores que realizaram autocitação, bem como o número total de autocitações feitas.

Quadro 1 - Autocitações.

\begin{tabular}{|c|c|c|c|}
\hline AUTOR & $\begin{array}{c}\mathbf{N}^{\circ} \text { de auto- } \\
\text { citações }\end{array}$ & AUTOR & $\begin{array}{c}\mathrm{N}^{\circ} \text { de auto- } \\
\text { ciatções }\end{array}$ \\
\hline Birdsong, L. & 6 & Seiler, V. & 3 \\
\hline Bothma, T. & 8 & Miil, K & 1 \\
\hline Scheepers, D. & 3 & Freire, G. H. A. & 2 \\
\hline Chu, S. K. W. & 3 & Morgan, M. K. & 1 \\
\hline Cmor, D. & 1 & Singh, N. & 1 \\
\hline Crawford, J. & 1 & Sokoloff, J. & 1 \\
\hline Irving, C. & 1 & Tan, S. M. & 1 \\
\hline Detlor, B. & 2 & Singh, D. & 4 \\
\hline Serenko, A. & 2 & Thornton, S. & 1 \\
\hline Detmering, R. & 1 & Sibthorpe, J. & 1 \\
\hline Diehm, R. A. & 2 & Saunders, L. & 1 \\
\hline Lloyd, A. & 12 & van Helvoort, A. A. J. & 4 \\
\hline Ford, P. J. & 1 & Weiner, S. A. & 1 \\
\hline Fosmire, $\mathrm{M}$ & 1 & Wilson, C. & 2 \\
\hline Gloria Ponjuán Dante, C. & 1 & Grettano, $\mathrm{T}$. & 1 \\
\hline Gross, M. & 7 & Thalluri, P. V. S. & 2 \\
\hline Latham, D. & 6 & Saleh, I. & 3 \\
\hline Gunton, L. & 1 & Webber, S. & 5 \\
\hline Bruce, $\mathrm{C}$. & 11 & Niemelä, R. & 2 \\
\hline Stoodley, I. & 1 & Ek, S. & 3 \\
\hline Hofer, A. R. & 1 & Eriksson-Backa, K. & 3 \\
\hline Townsend, L. & 1 & Huotari, M. L. & 4 \\
\hline Brunetti, K. & 1 & O'Brien, T. & 2 \\
\hline Vibbert, D. & 1 & Russell, P. & 2 \\
\hline Kumar, S. & 1 & Pinto, M. & 11 \\
\hline Ochoa, M. & 1 & Tirado, A. U. & 16 \\
\hline Ladell-Thomas, J. & 1 & Zgrabljić Rotar, N. & 1 \\
\hline Lai, H. J. & 2 & Erjavec, K. & 1 \\
\hline Lalor, J. G. & 1 & Leung, L. & 3 \\
\hline Špiranec, S. & 3 & Mery, Y. & 5 \\
\hline Reed, B. & 1 & Newby, J. & 3 \\
\hline Laverty, C. & 1 & Peng, K. & 1 \\
\hline
\end{tabular}




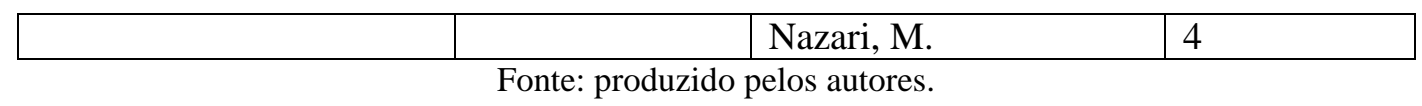

O diagrama da rede apresentado na figura abaixo (Figura 1) mostra as múltiplas ligações que representam as citações feitas ou recebidas pelos 214 autores participantes da rede. É como uma fotografia que mostra a situação especifica do momento ao considerar o recorte estabelecido e o contexto de desenvolvimento da pesquisa.

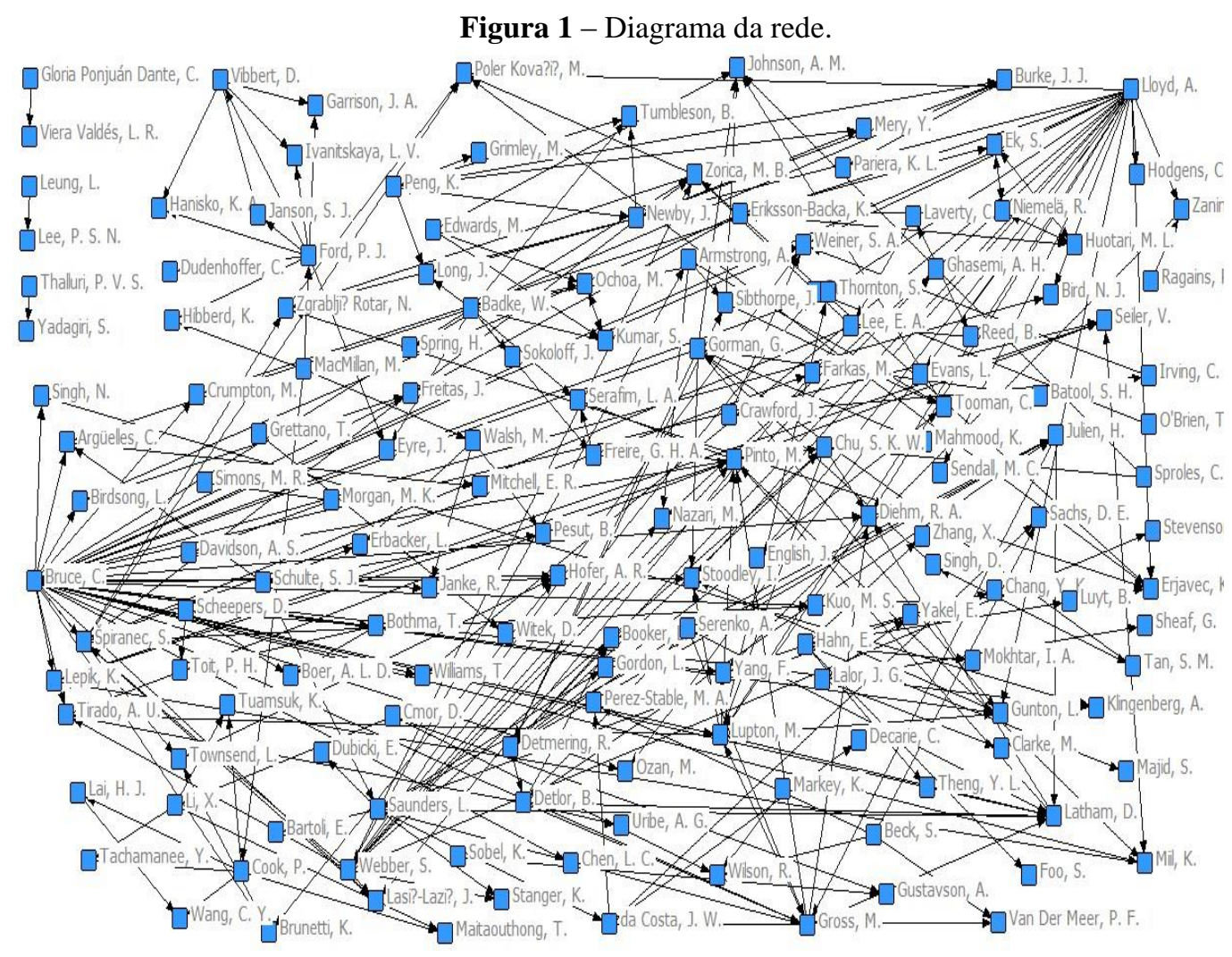

Fonte: produzido pelos autores.

A direção das ligações aponta os citantes e os citados. Assim, nota-se a existência de uma intensa ligação entre os autores que se citam, não sendo possível, por meio do diagrama, apontar a existência de clusters isolados.

O que se pode perceber é a existência de três pequenos grupos compostos por apenas dois autores cada um, que tiveram uma ligação, caracterizando uma díade. São eles: Gloria Ponjuán Dante, C. e Vera Valdes, L. R; Leung, L e Lee, P. S. N; e Thalluri, P. V. S. e Yadagirir, S. 
Na métrica de densidade, a rede mapeada neste trabalho apresentou 299 nós, ou seja, 299 ligações entre os 214 autores participantes. A princípio esse número pode parecer significativo, no entanto, como já dito, a densidade é calculada pelos números de ligações possíveis. Nesse caso, temos uma rede com muitos autores, então o número de ligações possíveis é extremamente grande.

A densidade calculada para a rede foi de $0,7 \%$, um número bastante baixo, que indica que não há um número considerável de citações entre os autores, ainda que os autores da rede se citem, isso ocorre num grau muito pequeno, indicando que há pouca interação entre os autores participantes da rede no que se refere à citação entre os mesmos.

Referente aos cliques, as maiores interações aconteceram entre os autores presentes no diagrama da Figura 2 que representa os quatro cliques encontrados na rede.

Figura 2 - Cliques.

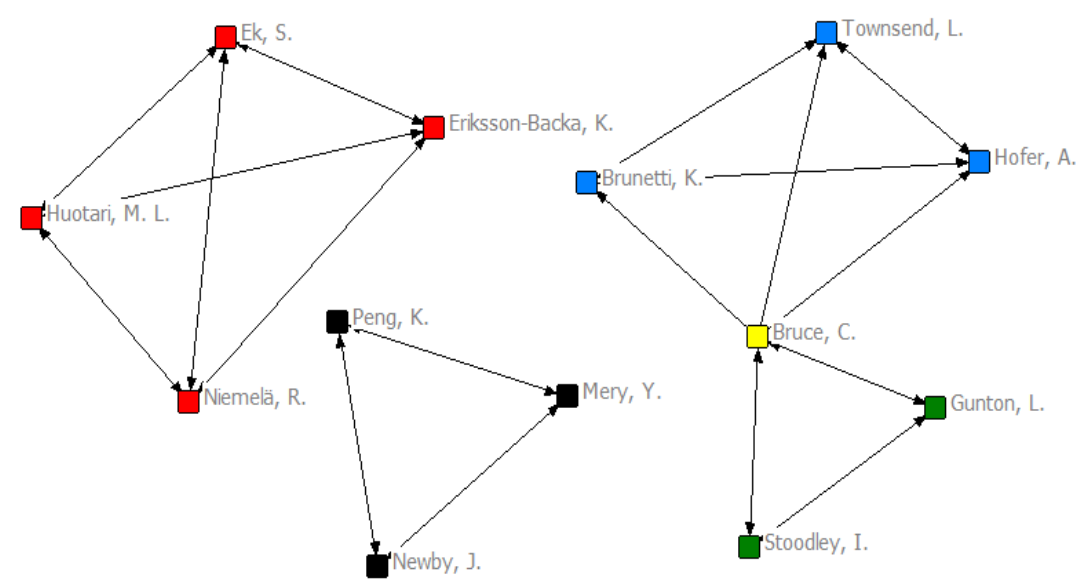

Fonte: produzido pelos autores.

O primeiro, representado pela cor vermelha, é composto pelos seguintes autores: Ek, Eriksson-Backa, Niemlä e Huotari. Esses quatro autores, como indica a direção das setas no diagrama, tiveram uma forte ligação, pois tanto citaram quanto foram citados pelos autores presentes neste clique. Pode-se inferir, tanto neste clique como nos demais, que a formação dos mesmos se dá por serem autores originários do mesmo país. No clique representado pela cor vermelha, os autores são da 
Finlândia. No clique representado pela cor preta, os autores Peng, Mery e Newby, são dos Estados Unidos. E o clique representado pela cor verde é composto por Stoodley, Gunton e Bruce, de origem australiana.

Esta última autora citada, Bruce, é a única autora que participa de dois cliques. Além daquele representado pela cor verde, Bruce também participa do clique representado pela cor azul, do qual participam também os seguintes autores: Hofer, Townsend e Brunetti, representantes dos Estados Unidos.

No âmbito deste estudo, os autores listados nos resultados de centralidade representam nomes importantes para a Competência em Informação, visto que são bastante citados ou citam seus colegas. Tal fato evidencia o nome desses pesquisadores como indivíduos que assumem uma atitude de intensa interação com seus pares. Neste estudo, foram aplicadas as seguintes medidas de centralidade: de grau, proximidade e intermediação.

Com relação à centralidade de grau, foram analisados os graus de entrada e de saída em que o grau de entrada é a soma das interações que os outros nós têm com o autor, já o de saída é a soma das interações que os nós têm com os outros.

O Quadro 2 mostra os resultados dos autores que tiveram um maior índice no que tange ao grau de entrada e de saída da rede analisada, são apresentados os 10 primeiros autores mais listados.

Quadro 2 - Centralidade de grau.

\begin{tabular}{|c|c|c|}
\hline Autor & Grau de entrada & Grau de saída \\
\hline Bruce, C. & 31 & 5 \\
\hline Lloyd, A. & 21 & 0 \\
\hline Webber, S. & 13 & 2 \\
\hline Badke, W. & 12 & 0 \\
\hline Hahn, E. & 8 & 0 \\
\hline Ford, P. J. & 8 & 1 \\
\hline Detlor, B. & 7 & 2 \\
\hline Detmering, R. & 7 & 2 \\
\hline Saunders, L. & 7 & 3 \\
\hline Gorman, G. & 7 & 2 \\
\hline
\end{tabular}

Fonte: produzido pelos autores.

Ao analisar o quadro, podemos ver os índices de centralidade de grau de entrada e saída. O grau de entrada representa as citações recebidas pelo autor originadas de outros membros da rede. Já o grau de saída representa o número de 


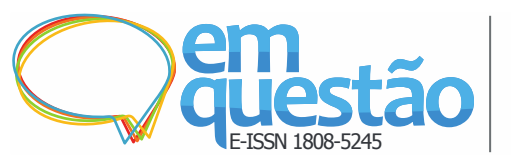

Redes de Citação: estudo de rede de pesquisadores a partir da competência em informação

Marcos Moraes, Renata Lira Furtado, Maria Inês Tomaél

citações feitas pelo autor em trabalhos de outros autores da rede em questão. Podemos perceber, nesse caso, que Bruce e Lloyd possuem uma posição bastante central no que se refere ao grau de entrada, pois são os autores mais citados entre aqueles que participam de sua rede, ambos sendo da Austrália. Webber e Badke também possuem uma posição privilegiada nesse aspecto, o primeiro representado pelo Reino Unido e o segundo, pelo Canadá. Quanto ao grau de saída, não percebemos, nesse quadro, um número muito expressivo, mesmo que Bruce continue em destaque.

Assim, ao analisarmos os graus de entrada e saída normalizados, temos uma representação percentual dos referidos graus. O quadro a seguir mostra essa representação.

Quadro 3 - Graus normalizados.

\begin{tabular}{|c|c|c|}
\hline Autor & $\begin{array}{c}\text { Grau de entrada } \\
\text { Normalizado }\end{array}$ & $\begin{array}{c}\text { Grau de saída } \\
\text { Normalizado }\end{array}$ \\
\hline Bruce, C. & 14.554 & 2.347 \\
\hline Lloyd, A. & 9.859 & 0.000 \\
\hline Webber, S. & 6.103 & 0.939 \\
\hline Badke, W. & 5.634 & 0.000 \\
\hline Hahn, E. & 3.756 & 0.000 \\
\hline Ford, P. J. & 3.756 & 0.469 \\
\hline Detlor, B. & 3.286 & 0.939 \\
\hline Detmering, R. & 3.286 & 0.939 \\
\hline Saunders, L. & 3.286 & 1.408 \\
\hline Gorman, G. & 3.286 & 0.939 \\
\hline
\end{tabular}

Fonte: produzido pelos autores.

Com a análise do grau de centralidade pudemos observar também os índices gerais de toda a rede que são representados no quadro abaixo.

Quadro 4 - Estatísticas gerais de grau de centralidade.

\begin{tabular}{|l|c|c|c|c|}
\hline Estatísticas & $\begin{array}{c}\text { Grau de } \\
\text { Saída }\end{array}$ & $\begin{array}{c}\text { Grau de } \\
\text { Entrada }\end{array}$ & $\begin{array}{c}\text { Grau de } \\
\text { Saída } \\
\text { Normalizado }\end{array}$ & $\begin{array}{c}\text { Grau de } \\
\text { Entrada } \\
\text { Normalizado }\end{array}$ \\
\hline Média & 1.397 & 1.397 & 0.656 & 0.656 \\
\hline Desvio-padrão & 3.222 & 1.481 & 1.513 & 0.695 \\
\hline Soma & 299.00 & 299.00 & 140.376 & 140.376 \\
\hline Variância & 10.380 & 2.193 & 2.288 & 0.483 \\
\hline Mínimo & 0.000 & 0.000 & 0.000 & 0.000 \\
\hline Máximo & 31.000 & 6.000 & 14.554 & 2.817 \\
\hline \multicolumn{5}{|c|}{ Fonte: produzido pelos autores. } \\
\hline
\end{tabular}


Apresentados os índices de grau de centralidade, também foram verificados os números relativos ao grau de proximidade. O quadro 5 mostra que os autores que mais se beneficiam dessa centralidade, ou seja, os autores listados abaixo, são os que têm uma maior facilidade em citar ou ser citado pelos seus colegas, tendo, desse modo, uma posição mais central na rede. Pode-se perceber, ao analisar os dados de proximidade, que os índices indicaram um número bastante aproximado entre os autores participantes da rede. Isso indica que não existe um autor específico que seja expressivamente independente para ser citado.

Quadro 5 - Índice de proximidade.

\begin{tabular}{|c|c|}
\hline Autor & Índice de Proximidade \\
\hline Poler Kovalic, M. & 0.551 \\
\hline Erjavec, K. & 0.548 \\
\hline Zgrabljik Rotar, N. & 0.548 \\
\hline Freitas, J. & 0.545 \\
\hline Zorica, M. B. & 0.543 \\
\hline Lasik-Lazik, J. & 0.543 \\
\hline Birdsong, L. & 0.543 \\
\hline Farkas, M. & 0.542 \\
\hline Weiner, S. A. & 0.540 \\
\hline Piranec, S. & 0.540 \\
\hline
\end{tabular}

Fonte: produzida pelos autores.

O Quadro 6 elenca os dez primeiros autores no que tange ao índice de intermediação. Observamos os autores que possuem uma independência e uma posição mais privilegiada no que se refere ao estudo em questão. Percebemos, também, que o autor melhor posicionado na rede, no que se refere à métrica de intermediação, é Christine Bruce.

Quadro 6 - Intermediação.

\begin{tabular}{|l|l|l|l|l|l|}
\hline \multicolumn{2}{|c|}{ Autor } & \multicolumn{1}{c|}{$\begin{array}{c}\text { Índice de } \\
\text { Intermediação }\end{array}$} & \multicolumn{2}{c|}{ Autor } & $\begin{array}{c}\text { Índice de } \\
\text { Intermediação }\end{array}$ \\
\hline $1^{\circ}$ & Bruce, C. & 659.833 & $6^{\circ}$ & Gross, M. & 131.958 \\
\hline $2^{\circ}$ & Lupton, M. & 527.042 & $7^{\circ}$ & Latham, D. & 131.958 \\
\hline $3^{\circ}$ & Saunders, L. & 216.000 & $8^{\circ}$ & Webber, S. & 97.000 \\
\hline $4^{\circ}$ & Chu, S. K. W. & 207.042 & $9^{\circ}$ & Piranec, S. & 71.000 \\
\hline $5^{\circ}$ & Pinto, M. & 144.667 & $10^{\circ}$ & Yakel, E. & 50.000 \\
\hline
\end{tabular}

Fonte: produzida pelos autores. 
A Figura 3 representa a rede da autora Christine Bruce. Observamos, no gráfico, que a autora recebeu muitas citações de trabalhos publicados anteriormente por outros autores participantes da rede. Além disso, a autora também foi citada por um número significativo de autores, o que reforça sua posição privilegiada no sentido de intermediação dentro da rede.

Figura 3 - Rede de Cristine Bruce.

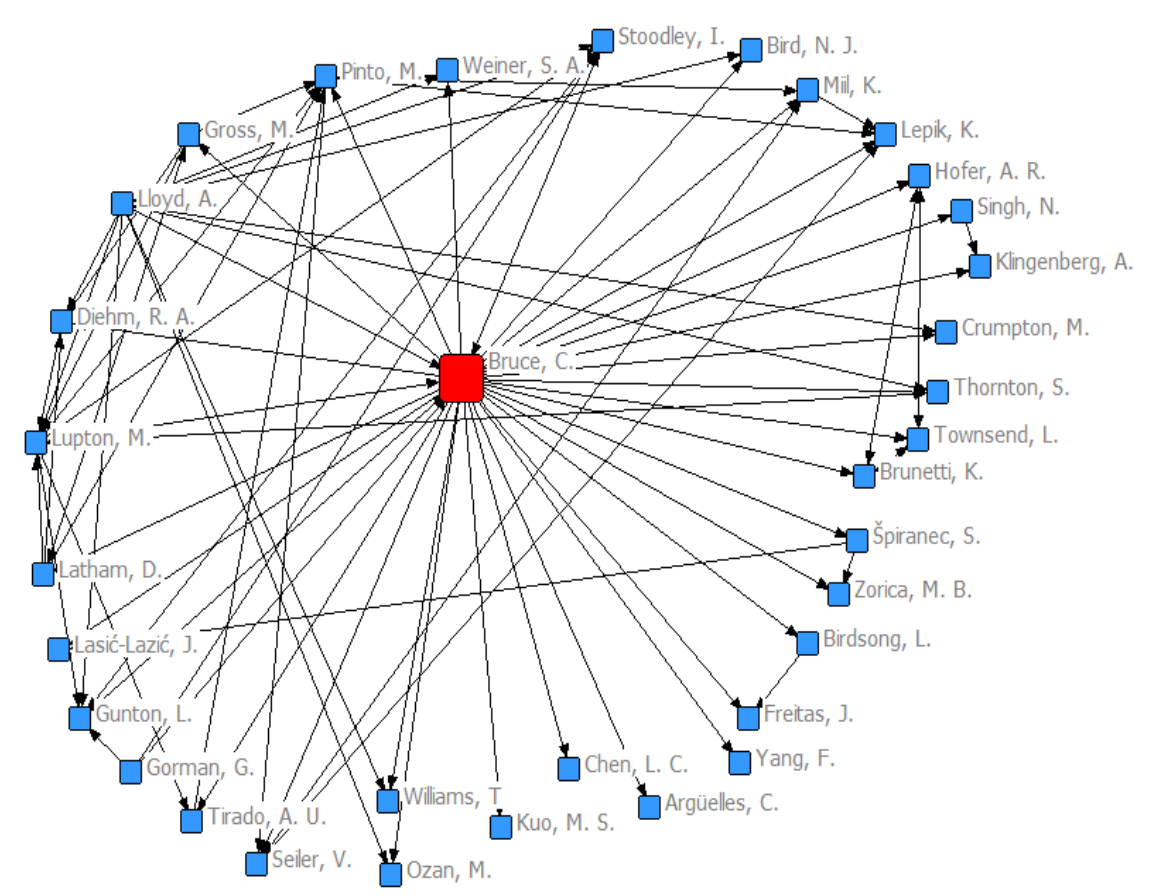

Fonte: produzida pelos autores.

\section{Considerações Finais}

Neste artigo, as métricas foram descritas seguindo os dados obtidos pelo UCINET. Com base nos resultados, pode-se perceber os diversos aspectos relacionados com a rede de citação composta pelos pesquisadores de Competência em Informação que tiveram seus trabalhos publicados ao longo do ano de 2012 na base de dados Scopus.

A densidade dessa rede foi muito baixa, ou seja, o índice de citação entre os pesquisadores elencados foi muito pequeno. Tal fato pode ser explicado por 
diversos fatores, por exemplo: a filiação teórica dos autores, que podem ser divergentes mesmo dentro de um assunto específico e a filiação institucional dos autores, visto que a cobertura geográfica da base de dados é bastante abrangente.

Um dado que merece discussão diz respeito à autocitação, recurso bastante utilizado pelos autores. A autocitação, como já dito, compreende o uso de ideias, conhecimentos e informações já publicados em trabalhos anteriores pelo mesmo autor do trabalho em que este é citado. Tal prática promove bastante discussão na comunidade acadêmica pelo motivo de que o uso de tal recurso interfere nos indicadores de avaliação e impacto da produção dos autores.

De uma maneira geral, percebemos a importância de determinados autores que apareceram como mais centrais, recebendo um maior número de citações pelos seus colegas. Destaca-se, entre esses autores, Christine Bruce, como uma autora que recebe muitas citações, assumindo uma posição de destaque na rede estudada.

Por fim, o estudo de redes de citação nas diversas áreas do conhecimento evidencia o comportamento e a interação entre os pesquisadores, levantando questões importantes como a baixa interatividade, que foi o caso da rede estudada neste trabalho. O estudo das questões que permeiam o funcionamento das redes auxiliam não somente na produção de conhecimento, como também no desenvolvimento de estratégias, produtos e serviços que otimizem o funcionamento destas redes, ocasionando um maior compartilhamento de informação e conhecimento que impulsionam a ciência em geral.

\section{REFERÊNCIAS}

AMERICAN LIBRARY ASSOCIATION. Report of the Presidential Committee on information literacy: Final Report. Chicago, 1989. Disponível em: <http://www.ala.org/acrl/nili/ilit1st.html >. Acesso em: 01 fev. 2014.

\section{ASSOCIAÇÃO BRASILEIRA DE NORMAS TÉCNICAS. Normas para citações e referências Bibliográficas. São Paulo: ABNT, 2003.}

DUDZIAK, E. A. A Information Literacy e o papel educacional das bibliotecas. 2001. Dissertação (Mestrado em Ciência da Comunicação) - Universidade de São Paulo, São Paulo, 2001. Disponível em: <http://www.teses.usp.br/teses/disponiveis/27/27143/tde-30112004-151029/>. Acesso em: 21 jun. 2014. 
GASQUE, K. C. G. D. Competência em Informação: conceitos, características e desafios. AtoZ: novas práticas em informação e conhecimento, v. 2, n. 1, p. 5-9, 2013. Disponível em: 〈http://www.atoz.ufpr.br/index.php/atoz/article/view/44>. Acesso em: 10 jul. 2014.

GRIFFITH, B. C. Understanding science; studies of communication and information. Communication Research, Newbury Park, v. 16, n. 5, p. 600-614, 0ct. 1989.

HATSCHBACH, M. H. L.; OLINTO, G. Competência em informação: caminhos percorridos e novas trilhas. Revista Brasileira de Biblioteconomia e Documentação, São Paulo, v.4, n.1, p. 20-34, jan./jun. 2008. Disponível em: <http://www.febab.org.br/rbbd/ojs-2.1.1/index.php/rbbd/article/view/64/78>. Acesso em: 23 jul. 2014.

HANNEMAN, R. A. Introduction to social network methods. 2001. Disponível em: 〈http://faculty.ucr.edu/ hanneman/nettext/index.html〉 . Acesso em: 26 ago. 2013.

HATSCHBACH, M. H. L. Information literacy: aspectos conceituais e iniciativas em ambiente digital para o estudante de nível superior. 2002. Dissertação (Mestrado em Ciência da Informação) - IBICT, UFRJ, Rio de Janeiro, 2002.

HORTON JR.; F. W. Understanding information literacy: a primer. Paris: UNESCO, 2008.

JAN, R. Citation analysis of Library Trends. Webology, Iran, v. 6, n. 1, Mar, 2009. Disponível em: 〈http://www.webology.org/2009/v6n1/a67.html>. Acesso em: 15 abr. 2013.

KADUSHIN, C. Understanding social networks: theories, concepts and findings. Oxford: Oxford Univerty, 2012.

KNELLER, G. F. A ciência como atividade humana. Rio de Janeiro: Zahar, 1980.

LAU, J. Diretrizes sobre desenvolvimento de habilidades em informação para a aprendizagem permanente. Boca Del Rio: IFLA, 2007. Disponível em: $<$ http://www.ifla.org/files/assets/information-literacy/publications/ifla-guidelinespt.pdf>. Acesso em: 20 jul. 2014.

LEMIEUX, V; OUIMET, M. Análise estrutura das redes sociais. Lisboa: Instituto Piaget, 2008.

MARTELETO, R. M. Analise de Redes Sociais: aplicação nos estudos de transferência da informação. Ciência da Informação, Brasília, v.30, n.1, p. 71-81, jan/abr. 2001. 
MARTELETO, R. M.; TOMAÉL, M. I. A metodologia de Analise de Redes Sociais (ARS). In: VALENTIM, Marta Lígia Pomim (Org.). Métodos qualitativos de pesquisa em Ciência da Informação. São Paulo: Polis, 2005.

MONEREO, C.; BADIA, A. La competencia informacional desde una perspectiva psicoeducativa: enseñanza basada em la resolución de problemas prototípicos y emergentes. Revista española de Documentación Científica, v. 35, n. Monográfico, p. 75-99, 2012. Disponível em: < http://redc.revistas.csic.es/index.php/redc/article/view/745/826>. Acesso em: 30 jul. 2014.

MOREL, R. L. de M.; MOREL, C. M. Um estudo sobre a produção científica brasileira, segundo os dados do Institute for Scientific Information (ISI). Ciência da Informação, Brasília, v. 6, n. 2, p. 99-109, 1977. Disponível em: <http://revista.ibict.br/ciinf/index.php/ciinf/article/viewFile/1677/1283>. Acesso em: 15 abr. 2014.

ROMANCINI, R. O que é uma citação? A análise de citação na ciência. Intexto, Porto Alegre: UFRGS, v. 2, n. 23, p. 20-35, julho/dezembro 2010. Disponível em: <http://seer.ufrgs.br/intexto/article/view/15885>. Acesso em 10 set. 2014.

SILVEIRA, M. A. A.; BAZI, R. E. R. As referências nos estudos de citação:algumas questões para discussão. Datagramazero, Rio de Janeiro, v. 10, n. 4, ago. 2009. Disponível em: 〈http://www.dgz.org.br/ago09/Art_04.htm>. Acesso em: 15 abr. 2013.

SOUSA, Paulo de Tarso Costa de. Metodologia de analise de redes sociais. In: MUELlER, S. P. M. (Org.) Métodos para a pesquisa em Ciência da Informação. Brasilis: Thesaurus, 2007.

TOMAÉL, M. I.; ALCARÁ, Adriana Roseclér; DI CHIARA, Ivone Guerreiro. Das redes sociais à inovação. Ciência da Informação, Brasília, v. 34, n. 2, p. 93-104, maio/ago. 2005

Citation Networks: a study of researchers' network in information literacy

Abstract: In scientific communication, researchers have been using the methodology of Social Network Analysis (ARS) in order to seek an investigation between the relationship of researchers/educational institutions and research, organizations and documents. This research fits into this context: the goal was to map the network of the authors' citations who published papers on Information Literacy at the Scopus database in the year of 2012. The Social Network Analysis (ARS) was used in conjunction with the technical aspects of the citation analysis concerning the reaching of the proposed goal. The network analyzed presented a 
degree of very low density, in other words: there was a low indication of citation among the authors. Differently, the self-citations were observed to be quite higher in comparison to the latter. It was established that certain authors have a great scientific importance once they are often cited by peers. It was observed that in the case of the network studied, Christine Bruce was identified as the most cited by peers. New researches can be made if another periods and communication channels can be analyzed in order to establish comparison so it can thicken the knowledge of this area researchers' behavior.

Keywords: Social network analysis. Citation networks. Information literacy. Citation analysis.

Recebido em: 31/05/2014

Aceito em: 23/06/2015 